\section{Acolhimento como prática interdisciplinar num programa de extensão universitária}

\author{
Shelter as an interdisciplinary practice \\ in a university extension program
}

Élida Azevedo Hennington 1

\title{
Introdução
}

1 Programa de

Pós-graduação em Ciências

da Saúde, Universidade

do Vale do Rio dos Sinos,

São Leopoldo, Brasil.

Correspondência

É. A. Hennington

Programa de Pós-graduação

em Ciências da Saúde,

Universidade do Vale

do Rio dos Sinos. C. P. 275,

São Leopoldo, RS

93022-000, Brasil.

henningt@bios.unisinos.br

\begin{abstract}
This article discusses the Interdisciplinary Health
Abstract

Promotion and Health Care Program at Vale do Rio dos Sinos University in Brazil. Beginning with an exploratory process, the study aims to analyze and comprehend the role of this community-oriented program in the education of students from different health-related disciplines at the University, as well as the program's health care role in the city of São Leopoldo, Rio Grande do Sul State, Brazil. The central concept is that of "acolhimento" ("refuge" or "shelter"). The program involves internship grants and services to the community and aims to enhance health-related practices in various fields such as Psychology, Nutrition, Nursing, Physical Education, and Collective Health, besides interfaces with Social Service, Law, and Medicine.
\end{abstract}

Health Promotion; Program Evaluation; Education
A Constituição da República Federativa do Brasil de 1988 define a educação como um direito de todos e dever do Estado e da família, visando ao pleno desenvolvimento da pessoa, seu preparo para o exercício da cidadania e sua qualificação para o trabalho. No seu artigo 207, determina que as universidades gozam de autonomia didático-científica, administrativa $\mathrm{e}$ de gestão financeira e patrimonial, e obedecerão ao princípio da indissociabilidade entre ensino, pesquisa e extensão.

Como bem salienta Runieri 1, esse artigo constitucional corrobora objetivos fundamentais da República Brasileira, quais sejam a construção de uma sociedade livre, justa e solidária, a garantia do desenvolvimento nacional, a erradicação da pobreza, a promoção do bem comum. Ou seja, no princípio da indissociabilidade da pesquisa-ensino-extensão, estão inseridas a justiça social, a solidariedade e a cidadania.

"A universidade é autônoma para eleger a forma como prestar essa extensão, para eleger a maneira como se dará essa indissociabilidade; $e$ a autonomia e a indissociabilidade tornam a universidade parceira do Estado. A universidade pública tanto quanto a privada recebem da sociedade insumos para oferecer esse tipo de trabalho. Na universidade pública, a sociedade financia inteiramente o trabalho universitário. Na universidade particular, a imunidade tribu- 
tária reflete também um financiamento social. O fim da autonomia e o fim da indissociabilidade é a sociedade, e é apenas em função da sociedade que esses princípios têm sentido no nosso ordenamento jurídico" 1 (p. 147).

Mesquita Filho 2, ao discutir sobre diferentes conceitos de extensão universitária existentes, chama a atenção para a exigüidade da literatura sobre o tema e também sobre as diferentes conotações que o termo apresentou e vem apresentando ao longo do tempo. Esses conceitos foram agrupados pelo autor em cinco categorias: a extensão como curso; a extensão como prestação de serviços; a extensão como complemento; a extensão como "remédio" e a extensão como instrumento político-social. Desse modo, discutiu o papel da extensão sob várias perspectivas: como uma simples oferta de cursos à população, apoiada em idéias oriundas da Europa; como prestação de serviços sociais seguindo o exemplo dos Estados Unidos; como promoção de qualquer evento pela universidade; como atividade filantrópica ou como qualquer tipo de relação e comunicação entre universidade e comunidade; como atividade complementar ao ensino e à pesquisa; como compensação às falhas do ensino regular, em especial, a alienação da realidade social e, finalmente, como instrumento institucional utilizado para manter a ordem vigente ou como reduto de agrupamento de pessoas progressistas dentro das universidades e instrumento de mudanças sociais.

A última edição do Plano Nacional de Extensão Universitária (http:www.sr5.ufrj.br/documentos/pne.doc, acessado em 26/Jul/2004), apresentado pelo Ministério da Educação, afirma o conceito de extensão como um processo educativo que possibilita a relação transformadora entre universidade e sociedade, articulando o ensino e a pesquisa, ressaltando que a intervenção na realidade não tem o objetivo de levar a universidade a substituir atribuições de responsabilidade do Estado.

Garantida constitucionalmente, a implementação da extensão nas universidades brasileiras tem-se constituído num processo caracterizado por avanços e retrocessos, definições e redefinições no plano acadêmico, político e institucional. Desde as primeiras experiências na Universidade de São Paulo no início do século passado, com a oferta de conferências públicas e gratuitas, passando pelo reconhecimento por parte do Ministério da Educação da extensão como atividade-fim na universidade e a necessidade da relação e comprometimento das instituições de ensino superior com a sociedade, culminando com seu estabelecimento como preceito constitucional, o papel da extensão oscila entre uma atuação ainda limitada, muitas vezes, meramente assistencialista, outras vezes, assumindo um papel mediador entre universidade e sociedade e, finalmente, como agente transformador, envolvido diretamente nas discussões de políticas e nas práticas sociais. Atualmente, centram-se as discussões no papel plural da universidade, seus compromissos sociais e responsabilidade na formação do profissional cidadão, na solução dos grandes problemas brasileiros e na garantia da participação das populações como sujeitos do processo e também nos aspectos referentes à institucionalização da extensão nas instituições de ensino superior (Plano Nacional de Extensão Universitária. http:www.sr5.ufrj. br/documentos/pne.doc, acessado em 26/Jul/ 2004) 3,4 .

Os programas de extensão universitária desvelam a importância de sua existência na relação estabelecida entre instituição e sociedade, consolidando-se através da aproximação e troca de conhecimentos e experiências entre professores, alunos e população, pela possibilidade de desenvolvimento de processos de ensino-aprendizagem a partir de práticas cotidianas coadunadas com o ensino e pesquisa e, especialmente, pelo fato de propiciar o confronto da teoria com o mundo real de necessidades e desejos. Na área da saúde, assumem particular importância na medida em que se integram à rede assistencial e podem servir de espaço diferenciado para novas experiências voltadas à humanização, ao cuidado e à qualificação da atenção à saúde.

No âmbito da Saúde Coletiva, os chamados "modelos tecno-assistenciais" 5 têm sido objeto de estudos e de intensos debates no campo, e experiências e práticas inovadoras têm sido desenvolvidas no Brasil, principalmente a partir do processo de municipalização dos serviços nos anos 90. Em todo o país, foram apresentadas e desenvolvidas uma gama de novas propostas, modelos e estratégias, tais como Sistemas Locais de Saúde, Cidades Saudáveis, Em Defesa da Vida, Vigilância da Saúde e, mais recentemente, programas do Governo Federal, Saúde da Família e Agentes Comunitários de Saúde 6,7,8,9.

O acolhimento surge no âmago das propostas de reorientação da atenção à saúde. Ele tem 
sido analisado como processo e estratégia fundamental na reorganização da assistência em diversos serviços de saúde no país, buscando a inversão do modelo tecno-assistencial de modo a contemplar o princípio da universalidade no atendimento e a reorganização do processo de trabalho. Trata-se de um dispositivo que vai muito além da simples recepção do usuário numa unidade de saúde, considerando toda a situação de atenção a partir de sua entrada no sistema $10,11,12,13,14,15,16$.

No presente artigo, apresenta-se uma reflexão sobre o Programa Interdisciplinar de Promoção e Atenção à Saúde (PIPAS) da Universidade do Vale do Rio dos Sinos (UNISINOS). Trata-se de um processo inicial, exploratório, visando analisar e compreender o papel desse programa de extensão na formação dos alunos de diversos cursos dessa instituição e sua in serção como um importante locus de atenção à saúde no município, tendo sua diretriz, o acolhimento, como norteador dessa análise.

\section{O Programa Interdisciplinar de Promoção e Atenção à Saúde}

A UNISINOS é uma instituição jesuítica, particular, comunitária, sem fins lucrativos, situada na cidade de São Leopoldo, Estado do Rio Grande do Sul, Brasil, fundada no ano de 1969. A extensão na universidade foi institucionalizada a partir de 1985 com a criação da Pró-Reitoria Comunitária e de Extensão, embora já fossem desenvolvidas, há mais tempo, atividades de extensão através de seus departamentos e centros de ensino 17.

Criado em 1996, o PIPAS funciona na antiga sede da universidade, no centro da cidade de São Leopoldo. O PIPAS apresenta como principais objetivos desenvolver atividades de extensão coadunadas com o ensino e a pesquisa, incentivar práticas coletivas e interdisciplinares em saúde e prestar assessoria e consultoria, constituindo-se num campo de estágio para alunos de graduação e de pós-graduação (http: //www.s aude.unisinos.br/programas/pipas, acessado em 07/Ago/2004).

O PIPAS presta atendimento à população do Município de São Leopoldo, que atualmente possui 193.547 habitantes 18 , e a moradores de outras cidades da região do Vale do Rio dos Sinos e até da capital do Estado, Porto Alegre, Rio Grande do Sul, Brasil. Tem como clientela crianças, adolescentes e adultos e oferece uma gama variada de serviços, sendo considerado de referência regional no atendimento psicológico e de nutrição. As principais atividades de atenção à saúde desenvolvidas no PIPAS são entrevistas de acolhimento, intervenções na área da psicologia, inclusive com atendimento especializado a crianças e adolescentes em situação de violência, consultas de enfermagem, atenção nutricional e ações de promoção à saúde, principalmente através de atividades em grupo. Oferece também cursos abertos à comunidade, atuando em creches, escolas e hospitais do município. Realiza cerca de 7.500 atendimentos/ano (incluindo primeiras consultas, retornos e atividades grupais) e recebe em torno de 400 alunos de graduação e de pós-graduação lato sensu ao longo do ano, sendo cerca de 150 fixos dentre curriculares, bolsistas e voluntários e conta, atualmente, com um total de 18 professores e 2 funcionários administrativos. Os alunos dos cursos regulares participam do estágio durante, no máximo, um ano e meio esse período de permanência do aluno varia de acordo com o tipo de inserção e de curso (Relatório do Programa Interdisciplinar de Promoção e Atenção à Saúde, 2002).

Estudo desenvolvido por Meneghel et al. 19 apontou como principais motivos de atendimento no PIPAS hipertensão arterial, depres são e diabetes mellitus. Atualmente, observase o aumento da demanda relacionada a problemas de adaptação/aprendizagem, mais precisamente, crianças e adolescentes com dificuldades de aprendizagem ou de relacionamento dentro da escola e/ou que apresentam comportamento hiperativo ou agressivo, "diagnosticados" geralmente pela professora ou pela família - além de indivíduos com transtor nos alimentares, especialmente, obesidade, e de um crescente número de casos envolvendo vítimas de violência, encaminhadas pelo Conselho Tutelar ou pelo Poder Judiciário.

O PIPAS está organizado em torno de $N u ́$ cleos Interdisciplinares e de Grupos Temáticos, instâncias que reúnem alunos e professores das diferentes áreas de conhecimento: Psicologia, Nutrição, Enfermagem, Educação Física, Saúde Coletiva, num modelo articulador de ensino, produção de conhecimento e atenção à saúde. Os núcleos constituem-se em espaços de discussão a partir da demanda trazida pelos usuários atendidos no acolhimento, e os grupos reúnem alunos e professores interessados em desenvolver atividades de pesquisa em torno de quatro grandes temas: "Violências", "Distúrbios e Síndromes Plurimetabólicas”, "Saúde na Infância e na Adolescência” e "Distúrbios do Comportamento Alimentar".

O PIPAS é reconhecido institucionalmente pela sua importância como campo de estágio e centro formador para a graduação e como um 
serviço de referência para o Poder Público; em muitos casos, o único especializado e acessível à população de baixa renda, principalmente nos casos de atenção psicológica e nutricional, que constituem a maioria dos atendimentos.

De implantação relativamente recente, no bojo do fim da estrutura departamental na UNISINOS, o PIPAS apresenta como grande trunfo a interdisciplinaridade, característica que lhe confere especificidade e riqueza, revelando-o como motivador de reflexões e palco de embates na medida em que é espaço de convivência e trabalho de uma massa crítica de professores e alunos de diferentes áreas do conhecimento, com origens, formação acadêmica e experiências de vida diversas, interagindo com pessoas que trazem toda sorte de sofrimentos expressos através de problemas de saúde (ou não), favorecendo uma renovada produção coletiva.

As práticas dos programas de extensão justificam-se plenamente ao colocarem o aluno em contato direto e precoce com o mundo real, vivência imprescindível para sua formação, permitindo a aplicação dos conhecimentos teóricos adquiridos na sala de aula em situações do dia-a-dia. Entretanto, ao favorecer esse contato, inevitavelmente surgem frustrações e a clara percepção da dificuldade de operar em situações concretas, entendendo que operar remete-nos a determinada ética e implicação no contexto social brasileiro de extrema desigualdade e injustiça - muito mais do que simplesmente aplicar uma técnica ou deslocar um conhecimento para fora dos muros da academia 20 . Ao relatar a história do PIPAS, Moraes 20 salienta a dificuldade de constituição do Programa: “Não foi-nem está sendo-algo fácil. $O$ processo de constituição de uma equipe interdisciplinar é muito doloroso. É jogo, como dissemos antes, que se deve jogar com muita paciência e perseverança. Falamos em jogo, porque a situação de jogo talvez seja a que melhor expresse o contexto interdisciplinar: há disputas, há confrontos, há dissimulações. Enfim, a micropolítica [Foucault, 1996], que conforma o poder em perpétua circulação nas instituições, tem aí o seu terreno fértil e, por isso, desafiador. Com toda certeza, os resultados são sempre mais criativos e renovadores, porque frutos desse embate de idéias" 20 (p. 17).

Sem ainda uma definição própria e precisa de seu papel no sistema de saúde do município, o PIPAS é hoje espaço de contradições, tensões e disputas no processo de consolidação e também enquanto projeto que pretende superar a função meramente assistencialista ou simplesmente mediadora para transformarse em lugar de transformação e de vital influên- cia nas políticas e práticas sociais na comunidade na qual está inserido. Buscando o entendimento dessa realidade que contempla as diversas interações do serviço - seu papel na formação de alunos, na prestação de assistência e sua inserção no sistema de saúde - voltamos o olhar para a estratégia de acolhimento adotada pelo PIPAS como principal diretriz na sua relação com o usuário.

\section{O processo de acolhimento no PIPAS}

Acolher significa oferecer ou obter refúgio, proteção ou conforto físico; proteger(-se), abrigar(-se), amparar(-se) 21. O acolhimento, mais do que uma simples prática de atendimento à população que procura o PIPAS, é considerado uma diretriz central do Programa que atravessa estruturalmente o processo de trabalho. Implantado no ano de 2001, do ponto de vista operacional, procurou reduzir a fragmentação dos atendimentos prestados pelas diversas áreas, resolver o problema da demanda e evitar as "listas de espera", substituindo a triagem pela intervenção, buscando resgatar princípios fundamentais da prática em saúde: integralidade, humanidade e cuidado 22,23. Nesse sentido, entendemos o acolhimento segundo as características expressas por Franco et al. 13 (p. 345), "O acolhimento propõe que o serviço de saúde seja organizado de forma usuário centrada, partindo dos seguintes princípios: (1) atender a todas as pessoas que procuram os serviços de saúde, garantindo a acessibilidade universal; (2) reorganizar o processo de trabalho a fim de que este desloque seu eixo central do médico para uma equipe multiprofissional - equipe de acolhimento -, que se encarrega da escuta do usuário, comprometendo-se a resolver seu problema de saúde; e (3) qualificar a relação trabalhador-usuário que deve dar-se por parâmetros humanitários, de solidariedade e cidadania".

Segundo Merhy 24, na perspectiva de resolver os problemas relacionados à atenção e de um modo diferenciado de trabalhar-se em saúde, não bastariam apenas mudanças organizacionais e aporte financeiro suficiente às instituições, mas seria preciso, além disso, a realização de profundas transformações no processo de trabalho - especialmente, do trabalho vivo em ato, incluindo o aspecto relacional trabalhador-usuário ao sobrevirem processos tecnológicos que colocam em jogo, num momento específico, questões cruciais como vínculo, responsabilização, compromisso, autonomia, resolutividade. É nesse chamado "espaço intercessor" que ocorrem o conflito, a possibilidade 
de mudança e do ato criativo, que permitem superar as barreiras e dificuldades no atendimento das necessidades de saúde. Fruto de construção teórica, o acolhimento deve ser considerado uma nova tecnologia de trabalho, situando-se no âmbito da denominada micropolítica do trabalho em saúde, em que o processo de trabalho torna-se espaço público, passível de discussão coletiva e de reorientações, permitindo a efetiva autogestão de trabalhadores e construção da autonomia dos usuários, obviamente, sem negar a importante e decisiva influência da macropolítica no contexto da saúde 24,25,26.

O processo de acolhimento no PIPAS se dá a partir de uma demanda espontânea e referenciada, principalmente por órgãos e instituições públicas tais como escolas, Conselho Tu telar, Juizado da Infância e Juventude e Promotoria Pública. O acolhimento ocorre de maneira diferenciada em relação aos centros de saúde em geral. Ao invés de uma equipe multiprofissional, o atendimento é realizado por alunos, os mais experientes de qualquer um dos cursos de graduação vinculados ao PIPAS. O número de vagas para novos atendimentos é de três consultas por dia. Os casos atendidos são levados à discussão nos núcleos interdisciplinares onde são apresentados pelo aluno responsável pelo atendimento que relata toda a história colhida a partir de um protocolo de atendimento individual, no qual constam informações demográficas e sócio-econômicas sobre o indivíduo e sua família, além da história clínica. A partir dessa apresentação, as histórias são discutidas, e, apontados possíveis encaminhamentos, sendo definido se existe ou não a possibilidade do Programa acompanhar o usuário a partir daquele momento.

Aparentemente, existe uma aprovação consensual entre os diversos atores (gestores, professores, pessoal de apoio e alunos) sobre a implantação desse dispositivo de intervenção institucional que orienta a recepção do usuário que chega ao serviço. Dentre os aspectos positivos do processo, são observados o contato do aluno com pessoas cujas demandas são as mais variadas e nem sempre restritas a sua área específica de conhecimento, o comprometimento e a responsabilização dos alunos em relação às pessoas atendidas e também a possibilidade de discussão num espaço de participação ampliada (núcleos interdisciplinares), que inclui alunos e professores de diferentes áreas e cursos, permitindo a reflexão e a busca de soluções e encaminhamentos de maneira interdisciplinar, aumentando a chance de uma resposta adequada aos problemas. Por outro lado, os núcleos apre- sentam-se como espaços usuais para a exteriorização de angústias pessoais, queixas e conflitos relacionados ao processo de acolhimento, decorrentes, na maioria das vezes, da pouca resolutividade e da impossibilidade de dar conta de toda a demanda que recorre ao PIPAS.

Embora o PIPAS esteja aberto ao atendimento de qualquer tipo de necessidade relacionada às áreas de saúde que lá se encontram representadas, o acolhimento não se configura como possibilidade de acesso universal como ocorre em várias experiências no serviço público, a partir do momento em que existem o limite do agendamento e a oferta de um número fixo de atendimentos por semana. Por outro lado, percebe-se, igualmente, a existência de um grande número de reacolhimentos que, além de nem sempre resultarem numa intervenção resolutiva ou em adequado encaminhamento posterior, acabam dando origem a frustrações tanto para usuários como para alunos e a uma concreta diminuição das vagas disponíveis para novos atendimentos. A princípio, o reacolhimento deveria ser uma tentativa de resolução do problema via escuta do usuário, podendo, em certas circunstâncias, constituir-se mesmo em espaço de intervenção, como na abordagem de situações mais simples de sofrimento psíquico, por exemplo, porém nem sempre é percebido e apropriado pelos estudantes como tal. Some-se a tudo isso a impossibilidade real de conhecimento daquilo que se coloca como prioritário para a atenção em termos de demanda de saúde, tendo em vista que continua existindo uma população que sequer chega ao Programa e uma restrição formal ao acesso do usuário, além da falta de delimitação de clientela em termos epidemiológicos e geográficos.

Na prática, o que deveria ser uma diretriz operacional do PIPAS acaba transformando-se numa instância burocrática, pouco acessível e resolutiva e que não permite a criação e sua constituição como espaço de reflexão e crítica, de autonomia e de possibilidade de autogestão dos sujeitos - o acolhimento, assumido enquanto diretriz visando à melhoria do atendimento prestado, passa a correr o risco de tor nar-se uma mera "triagem humanizada".

"Transcorrido o tempo, percebemos que mesmo implantado o 'acolhimento' no seu as pecto formal (burocrático), ele não se instituiu como um princípio ético do atendimento em saúde (cultura). Isto pode ser observado nas dificuldades dos Núcleos Interdisciplinares em promoverem discussões qualificadas, não se limitando aos 'encaminhamentos'” 27 (p. 2).

Pesquisa de avaliação realizada por Malta 15, na rede pública municipal de Belo Horizon- 
te, Minas Gerais entre gerentes e trabalhadores de saúde, já apontara como fatores positivos do acolhimento a priorização de casos, a ampliação do acesso, a maior humanização no atendimento aos usuários, a otimização do trabalho da enfermagem, o estímulo ao trabalho em equipe e o aumento do vínculo entre usuários e equipe. Como fatores negativos, foram referidos a maior sobrecarga de trabalho, o pouco apoio institucional às experiências em implantação, a inadequação da área física, a sobrecarga dos centros de saúde pelas atividades de atenção à demanda e a redução das atividades de prevenção. A autora chamou a atenção para alguns dos principais pontos negativos que foram o não equacionamento de problemas referentes à urgência, à referência hospitalar e ao apoio diagnóstico por parte da secretaria de saúde e a falta de decisão política para implantar o mesmo processo de mudança nos demais níveis do sistema. Trazendo essas questões para a realidade do PIPAS, percebemse semelhanças ao constatar-se, como uma das principais queixas de alunos e professores em relação ao acolhimento, a pouca capacidade resolutiva e a falta de infra-estrutura de apoio e de referência e contra-referência para o encaminhamento de usuários.

Essa realidade gerou desconforto, críticas e a necessidade de buscar alternativas para o acolhimento, o que resultou numa recente proposta de atendimento em grupo (Grupo de Acolhimento) na tentativa de resgatar os princípios que fundamentaram a implantação dessa diretriz no PIPAS, requalificando a discussão, criando alternativas metodológicas para a prática de acolhimento, experimentando a técnica grupal como uma dessas alternativas, oferecendo subsídios para um programa de treinamento, tudo isso com a pretensão de, no futuro, inclui-la na rotina do programa 23, confirmando Matumoto 10 quando afirma que, por ter como foco o usuário e suas necessidades de saúde, o acolhimento impõe a flexibilização das normas e rotinas dos serviços.

O mais auspicioso do processo é que esse insight criativo que surge a partir do ruído institucional revela a ainda vital capacidade do PIPAS de reconhecer-se, repensar e redirecionar sua prática a partir da insatisfação, percepção e crítica de seus sujeitos e que se tornou explícita em diversos espaços de interlocução (núcleos interdisciplinares, reuniões de alunos, reuniões de professores).

"Outra noção na micropolítica do trabalho em saúde é a do 'ruído'. Esse conceito parte da idéia de que, cotidianamente, ocorrem processos silenciosos nas relações entre os agentes institucionais até o momento em que esta lógica funcional é rompida. A ruptura dessa lógica normalmente é entendida como uma disfunção, um desvio do 'normal'. Esses ruídos, entretanto, devem ser percebidos como processos instituintes que abrem possibilidades de interrogação sobre o modo instituído e mostram distintos modos de caminhar. Cumpre conseguir captar e entender esses ruídos" 15 (p. 284).

Merhy et al. 27, ao analisarem o processo de trabalho em saúde em suas dimensões tecnológicas, explicitam as categorias tecnologias duras, representadas pelas máquinas, normas, estruturas organizacionais; tecnologias leveduras, representadas pelos saberes estruturados, normas e rotinas (como a clínica médica, a clínica psicanalítica, a epidemiologia etc.) e tecnologias leves (tecnologias de relações do tipo produção de vínculo, autonomização, acolhimento, gestão como uma forma de governar processos de trabalho). No caso do PIPAS, nota-se um movimento inovador em torno das tecnologias leves - a experiência do Grupo de Acolhimento acaba de ser implantada e nasce da crítica e da tentativa de superação do sentimento de impotência. Começa a delinear-se aquilo que Merhy 24 classifica como a manipulação dessas tecnologias do tipo soft que nada mais são do que nossas sabedorias, experiências, atitudes, compromissos, responsabilidades para produzir saúde, acreditando ser possível, como afirma Moraes 20, operar na realidade e na frustração daí gerada.

Desse modo, movidos por insatisfações e ansiedades e procurando alternativas ao modelo estabelecido no Programa, sujeitos desse processo decidiram pela criação de um outro espaço de acolhimento - uma proposta alter nativa e que, ao mesmo tempo, ampliasse o processo de acolhimento tradicional. Com o Grupo de Acolhimento, surge uma nova instância terapêutica, expande-se a forma de acolhimento, buscando-se ainda o delineamento de novos caminhos de interação trabalhador/aluno-usuário e resposta aos problemas de saúde e, quem sabe, a constituição de um verdadeiro espaço reflexivo, crítico e de autogestão, além de motivador para a reflexão e reorientação do espaço até então formalmente implantado. “... O trabalho em saúde não pode ser globalmente capturado pela lógica do trabalho morto, expresso nos equipamentos e nos saberes tecnológicos estruturados, pois o seu objeto não é plenamente estruturado e suas tecnologias de ação mais estratégicas se configuram em processos de intervenção em ato, operando como tecnologias de relações, de encontros de subjetividades, para além dos saberes tecnológicos estruturados" 26 (p. 120-1). 
Felizmente, ao resistir à captura do trabalho vivo pelas forças instituídas (tecnologias duras e leve-duras) - o trabalhador da saúde mostrase, mais uma vez, peculiar não só pelo saber específico, mas em sua capacidade de ação, de escuta e de relação com o sofrimento humano. No que há de idiossincrásico nessa interação reside a riqueza e a potencialidade para transformações, para a intervenção terapêutica e a efetiva produção de saúde - trabalhadores enquanto agentes capazes de transformar a realidade e, com criatividade, propor novos rumos. $\mathrm{O}$ acolhimento no PIPAS reflete esses processos no constante movimento de seus atores, seguindo o curso de reinventar-se a cada instante.

\section{As possibilidades e os limites do acolhimento: repensando o PIPAS}

No processo exploratório de aproximação e de (re)conhecimento desse locus de atenção à saúde que mistura prática e intervenção com processos de ensino-aprendizagem, construção de cidadania e formação de sujeitos éticos, tornase necessário discutir não só sobre os aspectos favoráveis de um programa de extensão uni versitária, mas também sobre alguns de seus principais impasses e contradições.

Ao tornar o acolhimento como objeto norteador dessa empreitada, fez-se a opção por trilhar a partir de um ponto de partida percebido como intrínseco e extremamente instigante desde o primeiro momento na medida que é assumido pela instituição como diretriz do programa.

O PIPAS apresenta-se com características atípicas do ponto de vista da assistência à saúde, pois, pela própria constituição dos cursos acadêmicos envolvidos e do corpo docente responsável, não havia a habitual caracterização de uma equipe e de um modus operandi centrado na figura do médico, mostrando-se um campo fértil e diferenciado para contribuir na análise de práticas de saúde, de saberes e de poderes instituídos. Ao mesmo tempo, ao propugnar a adoção de uma diretriz operacional e operacionalizadora, cujo cerne é o processo de trabalho, e o amálgama, toda a sorte de imbricações relacionais e estruturais como alicerce à constituição de um modelo tecno-assistencial alternativo que leve em conta os interesses dos usuários, o fortalecimento da autonomia dos sujeitos envolvidos (usuários, alunos, trabalhadores) e as necessidades de saúde, o PIPAS coloca-se como mais uma experiência singular na transformação cotidiana no modo de ope- rar o trabalho no interior dos serviços de saúde, contribuindo para um projeto potencialmente emancipador.

A especificidade de tratar-se de programa que procura combinar atenção à saúde e atividades acadêmicas de ensino e pesquisa impõe algumas peculiaridades e limites. Percebe-se, muitas vezes, dificuldade de definir suas prioridades de atuação e métodos para o alcance de seus objetivos, pois se situa no tênue limiar entre um programa que assume o compromisso de prestar atendimento a uma (grande) parcela da população não assistida pelo sistema público de saúde e outro cuja missão é oferecer um campo de ensino-aprendizagem adequado aos seus alunos, abarcando uma pluralidade de orientações teórico-metodológicas na formação discente e na atenção prestada às pessoas que procuram o serviço.

Outro ponto a ser destacado é que o PIPAS convive com problemas decorrentes da falta de adscrição de sua clientela, ou seja, não está formalmente estabelecida sua área de abrangência, o que contribui fortemente para dificultar a organização do atendimento. Acrescente-se a isso o fato de (querendo ou não) fazer parte de um sistema de saúde pouco estruturado e de escassos recursos ofertados nas áreas específicas (principalmente, saúde mental e nutrição), que o coloca, para a população em geral, apesar das limitações de acesso já citadas, como a única alternativa de atendimento gratuito e de boa qualidade. Por outro lado, comprometido com uma formação generalista, o PIPAS é, ao mesmo tempo, responsável por atendimentos altamente especializados, respondendo não só à área da saúde, mas também à esfera jurídicoassistencial.

Finalmente, ao tornar o acolhimento problema e objeto de investigação, Matumoto 10 coloca uma das questões fundamentais que precisam ser enfrentadas ao mergulharmos na discussão sobre a reorganização de serviços de saúde e a implantação de modelos tecno-assistenciais - o papel do trabalhador de saúde, aquele que opera a intervenção, o agente com potência de ação e transformação: "Este homem, trabalhador de saúde, vive processos que interferem sobre o acolhimento, sobre seu posicionamento na relação. Refiro-me aos processos de reconhecimento do seu próprio trabalho, da percepção que tem de si como trabalhador, da representação de seu local de trabalho, das condições em que o realiza, da satisfação que pode obter dele. Incluo ainda sua preparação técnica e emocional, o espaço-tempo que destinará ao trabalho e ao atendimento, a disponibilidade para a escuta, para ser continente, identificar $e$ 
ir além do que está sendo dito, aguardar pelo espaço-tempo necessário à intervenção, sobre o quanto irá responsabilizar-se, sobre a forma como lançará mão das tecnologias do trabalho em saúde, isto nada mais é que o trabalhador, enquanto um ser com necessidades, tanto quanto o usuário" 10 (p. 206).

Essa questão necessita ser tratada com maior profundidade nos fóruns de discussão do PIPAS. É preciso ainda aprimorar a forma de participação e envolvimento dos representantes das diversas áreas de conhecimento no projeto de atuação interdisciplinar, fortalecendo a solidariedade e propiciando o surgimento do chamado trabalhador coletivo 24 . O estímulo à experiência multiprofissional e interdisciplinar propicia a ampliação do campo de competência 28 através de troca de saberes, levando a um notório ganho em termos de qualidade na atenção à saúde, sem que necessariamente se percam as especificidades e saberes próprios de cada profissão ou especialidade.

O acolhimento, como diretriz de um programa de extensão universitária e dispositivo na constituição de um novo modelo de atenção à saúde, precisa ser avaliado, rediscutido cotidianamente nos seus objetivos e aprimorado na sua implementação. O trabalho rotineiro de atendimento à demanda e as necessidades de aquisição de conhecimento e da aprendizagem de técnicas por parte dos alunos não devem, de modo algum, criar obstáculos à reflexão, à criatividade, ao diálogo com outras propostas originais e bem-sucedidas de atenção e à possibilidade de reorganização e mudanças na estruturação do serviço, principalmente tratando-se de um programa desenvolvido por uma instituição universitária.

\section{Considerações finais}

Não sem conflitos ou contradições, o PIPAS vem-se constituindo em espaço permanente de reflexão e de redefinição de metas e prioridades. As discussões internas incluem propostas inéditas de atendimento à população, a implantação de novos grupos de discussão e pesquisa, a integração com os outros programas de extensão universitária, a reestruturação e reorganização interna e externa em relação às políticas institucionais ditadas e assumidas publicamente pela universidade, o debate político sobre sua inserção no âmago do sistema de saúde do município. Enquanto se aguarda o desenrolar da peleia, nessa arena de disputas entre os diversos atores sociais, sujeitos-trabalhadores repensam o seu trabalho e, no fazer diário, propõem mudanças, abrindo linhas de fuga do instituído. Conforme Merhy et al. 27, caberia aos gestores desenvolver a capacidade de ouvir esses "ruídos" e, a partir dessa escuta, (re)significar o trabalho, reinventando missões institucionais.

Espera-se que, ao invés de produzir alienação e estranhamento, o PIPAS prossiga investindo na relação trabalhador-usuário, na aproximação do trabalhador/aluno do resultado de sua intervenção, valorizando e apoiando as pessoas e os resultados obtidos, abrindo espaço para a criatividade e a autonomia profissional mesclada com a responsabilização através do vínculo. No caso do PIPAS, trata-se de pensar o programa a partir de sua vocação interdisciplinar e sua tarefa num duplo sentido: o da atenção à saúde, qualificada e centrada nas necessidades dos usuários e orientada pelos pressupostos constitucionais de universalidade, integralidade e eqüidade e como parte integrante do SUS, aliado à responsabilidade de formação de seus alunos como sujeitos competentes e éticos.

Trata-se de uma missão complexa e de extrema relevância não só para o programa em si, mas para a própria universidade que assumiu como seus princípios a formação integral da pessoa humana, sua capacitação ao exercício profissional e atuação solidária para o desenvolvimento de toda a sociedade. Um desafio que se coloca a todos nós, gestores, professores, alunos, trabalhadores da saúde. Como uma experiência inovadora no âmbito da universidade, espera-se que o PIPAS, assim como todos os outros programas de extensão, continue se recriando e tendo fortalecido o seu papel acadêmico estratégico na formação dos alunos como sujeitos, profissionais competentes nos seus campos de atuação e comprometidos com a saúde das pessoas. O desafio que se coloca ao PIPAS é o de superar as dificuldades, inventar e reinventar maneiras novas e cada vez melho res, mais criativas, mais capazes de dar conta de produzir saúde e cidadania e contribuir na construção de um país mais justo e solidário. 


\section{Resumo}

O presente artigo apresenta uma reflexão sobre o Programa Interdisciplinar de Promoção e Atenção à Saúde da Universidade do Vale do Rio dos Sinos. Trata-se de um processo inicial, exploratório, visando analisar e compreender o papel desse programa de extensão na formação dos alunos de diversos cursos dessa instituição e sua inserção como um importante locus de atenção à saúde no Município de São Leopoldo, Rio Grande do Sul, Brasil, tomando como norte o processo de acolhimento, considerado uma de suas principais diretrizes. O Programa, campo de estágios e de prestação de serviços, tem como objetivo principal desenvolver práticas em saúde e envolve atualmente as áreas de conhecimento da Psicologia, Nutrição, Enfermagem, Educação Física, Saúde Coletiva, mantendo interface com o Serviço Social, o Direito e a Medicina.

Promoção da Saúde; Avaliação de Programas; Educação

\section{Agradecimentos}

Agradeço a leitura atenciosa e crítica da Profa. Stela Meneghel.

\section{Referências}

1. Runieri NBS. O princípio da indissociabilidade de ensino pesquisa e extensão do ponto de vista constitucional. Integração, Ensino, Pesquisa, Extensão 1997; III:146-8.

2. Mesquita Filho A. Integração ensino-pesquisaextensão. Integração, Ensino, Pesquisa, Extensão 1997; III:138-43.

3. Bemvenuti VLS. Extensão universitária. In: Bemvenuti VLS, organizador. Cadernos de Extensão UNISINOS I. São Leopoldo: Editora Unisinos; 2000. p. 17-27.

4. Hupffer HM, Bemvenuti VLS. Refletindo sobre a extensão universitária: novos caminhos de abertura da universidade à sociedade. In: Hupffer HM, organizador. Cadernos de Extensão UNISINOS III. São Leopoldo: Editora Unisinos; 2003. p. 9-17.

5. Merhy EE. A saúde pública como política. São Paulo: Editora Hucitec; 1992.

6. Mendes EV, organizador. Distrito sanitário: o processo social de mudança das práticas sanitárias do Sistema Único de Saúde. 2a Ed. São Paulo: Editora Hucitec/Rio de Janeiro: ABRASCO; 1994.

7. Silva Jr. AG. Modelos tecno-assistenciais em saú de: o debate no campo da Saúde Coletiva. São Paulo: Editora Hucitec; 1998.

8. Teixeira C, organizador. Promoção e vigilância da saúde. Salvador: Instituto de Saúde Coletiva; 2002.

9. Bodstein R. Atenção básica na agenda da saúde Ciênc Saúde Coletiva 2002; 7:401-12.

10. Matumoto S. O acolhimento: um estudo sobre seus componentes e sua produção em uma unidade da rede básica de serviços de saúde [Dissertação de Mestrado]. Ribeirão Preto: Escola de Enfermagem, Universidade de São Paulo; 1998.

11. Franco TB, Bueno WS, Merhy EE. O acolhimento e os processos de trabalho em saúde: o caso de Betim, Minas Gerais, Brasil. Cad Saúde Pública 1999; 15:345-53.

12. Leite JCA, Maia CCA, Sena RR. Acolhimento: perspectiva de reorganização da assistência de enfermagem. Rev Bras Enfermagem 1999; 52:161-8.

13. Camelo SHH, Angerami ELS, Silva EM, Mishima SM. Acolhimento à clientela: estudo em unidades básicas de saúde no município de Ribeirão Preto. Rev Latinoam Enfermagem 2000; 8:30-7.

14. Brêda MZ, Augusto LGS. O cuidado ao portador de transtorno psíquico na atenção básica de saúde. Ciênc Saúde Coletiva 2001 6:471-80.

15. Malta DC. Buscando novas modelagens em saúde: as contribuições do projeto vida e do acolhimento para a mudança do processo de trabalho na rede pública de Belo Horizonte: 1993-1996 [Dissertação de Mestrado]. Campinas: Faculdade de Ciências Médicas, Universidade Estadual de Campinas; 2001.

16. Ramos DD, Lima, MADS. Acesso e acolhimento aos usuários em uma unidade de saúde de Porto Alegre, Rio Grande do Sul, Brasil. Cad Saúde Pública 2003; 19:27-34.

17. Hupffer H. Situando a extensão na Unisinos. In: Bemvenuti VLS, organizador. Cadernos de Extensão UNISINOS I. São Leopoldo: Editora Unisinos; 2000. p. 9-15.

18. Instituto Brasileiro de Geografia e Estatística. Cen- 
so demográfico 2000. Resultados do universo. http://www.ibge.gov.br (acessado em 22/Set/ 2003).

19. Meneghel SN, Moraes FA, Cavedon M, Sato I, Wunder AP, Steffen H, et al. Avaliação de um serviço de promoção à saúde - 1999. In: Bemvenuti VLS, organizador. Cadernos de Extensão UNISINOS I. São Leopoldo: Editora Unisinos; 2003. p. 7-16

20. Moraes FA. Interdisciplinaridade como prática. In: Bemvenuti VLS, organizador. Cadernos de Extensão UNISINOS II. São Leopoldo: Editora Unisinos; 2000. p. 9-18.

21. Dicionário Houaiss de Língua Portuguesa. Rio de Janeiro: Objetiva; 2001.

22. Benetti S, Ramires VRR. A extensão e a construção do conhecimento no campo da saúde como locus para uma prática transdisciplinar. http:// www.saude.unisinos.br/revista-info/ano3num4/ Artigos/a34001.htm (acessado em 07/Ago/2003).

23. Damra A, Silveira, GK, Moraes, FA. Projeto: grupo de acolhimento. PIPAS. São Leopoldo: Universidade do Vale do Rio dos Sinos; 2003.

24. Merhy EE. Em busca da qualidade dos serviços de saúde: os serviços de porta aberta para a saúde e o modelo tecno-assistencial em defesa da vida. In: Cecílio LCO, organizador. Inventando a mudança na saúde. São Paulo: Editora Hucitec; 1994. p. 117-60.
25. Cecílio LCO. Inventando a mudança na saúde. São Paulo: Editora Hucitec; 1994.

26. Merhy EE, Chakkour M, Stéfano E, Stéfano ME, Santos CM, Rodríguez RA, et al. Em busca de ferramentas analisadoras das tecnologias em saúde: a informação e o dia-a-dia de um serviço: interrogando e gerindo trabalho em saúde. In: Merhy EE, Onocko R, organizadores. Agir em saúde: um desafio para o público. São Paulo: Editora Hucitec; 1997. p. 113-50.

27. Merhy EE. Em busca do tempo perdido: a micropolítica do trabalho vivo em saúde. In: Merhy EE, Onocko R, organizadores. Agir em saúde: um desafio para o público. São Paulo: Editora Hucitec; 1997. p. 71-112.

28. Campos GWS. Subjetividade e administração de pessoal: considerações sobre modos de gerenciar o trabalho em equipes de saúde. In: Merhy EE, Onocko R, organizadores. Agir em saúde: um desafio para o público. São Paulo: Editora Hucitec; 1997. p. 229-66.

Recebido em 28/Jan/2004

Versão final reapresentada em 05/Ago/2004

Aprovado em 15/Set/2004 